\title{
Digital Economic and Social Systems to be Featured by Stakeholders
}

\author{
Hiroshige Tanaka* \\ Professor Emeritus of Public Economics, Chuo University Tokyo, Japan
}

Submission: July 09, 2020; Published: July 30, 2020

"Corresponding author: Hiroshige Tanaka, Professor Emeritus of Public Economics, Chuo University Tokyo, Japan

\section{Abstract}

Digital economic systems have integrated consumption and production totally and complexly in a centralized framework. Moreover, development of digital economies has revived significant problems of social security. No one can explore economic systems by separating social issues. To achieve sustainability in global societies we must obtain the design of blueprint for the global economic mechanism. This paper presents one theoretical framework to analyze the digital structure of economies to recreate more sustainable social system. Exploration on structural change of stakeholders involved by innovation of ICT leads to solve theoretically some complicated problems which occurred in the digitalization of economies and societies. Transaction costs of stakeholders are efficient indexes for an integrated analysis on the digitalization of economies and societies.

Keywords: Centralized Scheme; Covid-19; Digitalization of economies and societies; Innovation of ICT; Outside stakeholders; Transaction Costs of Stakeholders; Voluntary Provision of Efforts

\section{Introduction}

In 2020, Covid-19 Pandemic makes locally and globally serious damages on economic and social systems. Digital economies have developed globally efficient economic and social systems. However, global transportation mechanisms unfortunately facilitate this serious disease to spread. To prevent the disaster from expanding, many counties and regions locked down integrated economic and social activities. Eventually, the pandemic easily has succeeded disturbing sophisticated system of digitalized economies and societies. Although development of digital technologies constructs efficient network systems of economies and societies, this network societies and economies appear to be vulnerable for risks of external economies. The digitalization of economies and societies has unprecedently evolved global economies. Many local economies are complexly connected with each other. If global system of economies and societies becomes at the peril of crises, it takes a great cooperative effort to correct the global problems. On the other hand, some digital technologies to be saved from infection of Covid-19 contribute to social services. For example, remote works and digital transactions are prevailing in the crises. By experiencing this pandemic, the digitalization of economies and societies will transform but procced forward steadily. Although innovation occurs spontaneously, a cooperative scheme to share information and to coordinate behaviors is necessary to improve social welfare. To achieve sustainability in global societies we must obtain the design of blueprint for the digital economic mechanism. We should construct one theoretical framework to analyze the digital structure of economies to recreate more sustainable social system. This paper argues that exploration on structural change of stakeholders involved by innovation of ICT leads to solve theoretically some complicated problems that occurred in the digitalization of economies and societies.

In the context of stakeholder structure, this paper presents an integrated analysis on economies and societies in the digital revolution. In decentralized framework Tanaka [1] explores a sustainable corporation to improve communication with two types, positive and negative, of stakeholders. In the $21^{\text {th }}$ century innovation of ICT has shrunk large manufactural industries and raised new global industries.

Declining employees of manufactural factories and raising businesses in ICT industry fundamentally change the structure of stakeholders in regions ${ }^{1}$. The new industrial revolution proceeds mainly in the centralized scheme but reforms indirectly connective

${ }^{1}$ Many researchers explore impacts by the innovation on the society from various aspects. By using many case studies, Baecker [2] explores comprehensively how digital innovation alters our society. 
relations in social communications and markets. Structural changes of stakeholders are supposed to feature diversification of economies and regions. Tanaka [3] explores that the comparative valuation by the two types stakeholders makes effective indication for sustainable global communities. When the digitalization of economies and societies prevails in global economies, we should make clear the condition that growing digital economies influence on sustainability of communities. Tanaka [4] argues that innovation of digital technologies raises outside stakeholders and that the unbalanced growth of stakeholders causes structural change of stakeholders. This structural change becomes one of the driving powers to propel the digitalization of economies and societies. The digitalization of economies and societies needs to expand traditional theories of industrial organization developed by Williamson [5-8] and others into theories of stakeholder structure. To provide a theoretical foundation on global industrial organization accompanies a new classification of transaction costs.

A network formulation to be explored integrates various various types of transactions developed by suppliers and consumers. This paper theoretically makes clear why innovation of ICT brings about revolutionary changes of global industries and provides a method of welfare analysis on digital economies. To feature the structural change of stakeholders indicates a significant index of social welfare in this industrial revolution. This paper is organized as follows. Section 2 features stakeholders to bring about the digitalization of economies and societies. To explore ramification of this industrial revolution we analyze comparatively centralized and decentralized social systems. Global economies are developed by basing on the centralized scheme and should be reviewed in the decentralized scheme. This section focuses on rapidly rising outside stakeholders brought by the digitalization of economies and societies. The outside stakeholders are assumed to correspond to negative stakeholders in the decentralized context. This revolution lowers the transaction cost regarding outside stakeholder. Section 3 demonstrates that every stakeholder contributes innovation voluntarily and that outside stakeholders make a main force to propel the digitalization of economies and societies. Section 4 describes the transaction costs of stakeholders. The transaction costs explain a scheme that the corporation provides payments on stakeholders. Section 5 demonstrates theoretically that innovation of ICT increases absolutely and relatively outside stakeholders and that external stakeholders partially divide into inside and outside stakeholders. Section 6 suggests that transaction costs will be an effective approach to explore problems of Covid-19 Pandemic.

\section{Digital Economies and a Sustainable Social System}

Digital economies are performing globally remarkable growth and expected to bring revolutionary changes on our communities. We should provide a theoretical method to explore sustainability of digital economies. Competition in markets dominates digital economies but mitigation of social losses from the revolution is brought by a framework of decentralization as follows.

In the multi stakeholders communities, the production of the corporation and its payment for the stakeholder $i$ are stated by $x$ and $t_{i}$. The stakeholder $i(i=1, \ldots, n)$ is supposed to evaluate the performance of it by $v_{i}\left(x, t_{i}\right)$. This function is assumed to be increasing with $t_{i} ; \frac{\partial V_{i}\left(x, t_{i}\right)}{\partial t_{i}} \geq 0$.

The centralized economic system is vulnerable to market and government failures to bring unsustainable economies and societies. To restore sustainability, we should insert a decentralized scheme into the vulnerable centralized system. Tanaka (9) discusses sustainability in the decentralized system by dividing stakeholders into the positive and the negative stakeholders to be defined by

$$
\frac{\partial V_{i}\left(x, t_{i}\right)}{\partial x} \geq 0 \frac{\partial V_{i}\left(x, t_{i}\right)}{\partial x}<0 .
$$

This paper theoretically explores how the digital revolution influences on sustainability by focusing on reconstruction of stakeholders. The corporation is supposed to perform production activity $x$ and to obtain the net private profit $\Pi(x)$ in the market transaction. Innovation of ICT has evolved the market system. Generally speaking, the corporation provides goods and services to consumers in a one-way market transaction from supply to demand. Tanaka (4) supposes that an innovation of ICT has been improving two-way communication in the framework of centralized schemes. To explore the innovation of communication system Tanaka [4] employs the approach to bring a classification of inside, outside, and external stakeholders. Economic activities of the corporation bring differentially social cost among stakeholders. To achieve sustainability the social system should allocate appropriately the social costs on the corporation. This classification makes clear that the corporation brings differentiated social costs to each type of stakeholders. In the transaction among the corporation and stakeholders' particular contracts or trusts are possible to be used beyond market relations. These social costs make additional information to the market prices. To develop sustainability the corporation should take the payment $t_{i}$ for the stakeholder $i$ to complement ordinal market transactions. To analyze theoretically, Tanaka [4] classifies stakeholders as follows. The corporation ordinally contacts many stakeholders in the market and could make particular contracts supplementary with some stakeholders. The former stakeholder is referred as the inside stakeholder and the latter stakeholder is named as the outside stakeholder. The inside stakeholders include main customers, business partners and employees. Consumers or suppliers using internet ${ }^{2}$ are supposed to exhibit a representative example of the outside stakeholders. The outside stakeholders are supposed to obtain less relevant interest and to be more occasional with the corporation than the inside stakeholders. The economic and social systems evolved by

${ }^{2}$ Hindman (10) explores the growth of internet economy and discusses that some monopolistic firms appear and influence seriously on societies and politics. 


\section{Annals of Social Sciences \& Management studies}

innovation of ICT bring social costs not only on the communities but also on the corporation. To survive rapidly changing digitalization of economies and societies the corporation should improve the evaluation of organization in both economic and social aspects. The social costs in the digitalization of economies and societies is partially burdened with transaction costs in the social systems. However, the corporation is not easy to conceive the transaction costs in ordinal activities. If we could formally evaluate transaction costs in the digital economies, they present a significant index on decrease of social loss or organizational efficiency. This classification of stakeholders facilitates to make clear the impact on the digitalization of economies and societies with a new terminology of transaction costs. In this paper we do not attempt to achieve general theory of the digital social system but only explore the social structural change in the digitalization by applying this method.

It is assumed that outside stakeholders are connected with the corporation mainly by networks of the internet. Development of digital technology enhances the quality of communication and enable the outside stakeholder to require a differentiate compensation for the transaction with the corporation. Markets of internet become to make possible to differentiate pricings of goods and services for particular transaction. While consumers in the shopping of internet market depend less on the limited corporations than the inside stakeholders such as employees, enlargement of internet services could take the outside stakeholders benefits yielding from lowering prices. That is, the innovation of digital technology makes the outside stakeholder obtain decreasing evaluation of the corporation regarding production $x$. To advance the reasoning of Tanaka [4] we rewrite the same Assumption 1 as before.

Assumption 1: Inside stakeholders consist of positive stakeholders. Outside stakeholders satisfy the definition of the negative stakeholders ${ }^{3}$.

In the digitalization of economies and societies we exhibit theoretically the objective function NB of net benefit by the expression (1) ${ }^{4} . n$ stakeholders are divided into inside stakeholders, $1 \ldots, n_{0}$, outside stakeholders, $n_{0}+1, \ldots, n_{1}$, and

$$
N B=\Pi(x)+\beta(x) \sum_{t=1}^{n_{0}(y)}\left\{V_{i}\left(x, t_{i}\right)-y_{i}\right\}+\gamma(y) \sum_{i=n_{0}(y)+1}^{n_{1}(y)}\left\{V_{i}\left(x, t_{i}\right)-y_{i}\right\}-t
$$

external stakeholders, $n_{1}+1, \ldots, n$. In the centralized scheme the corporation does not include the evaluation of the external stakeholders in the objective function. In the net benefit of the corporation $\beta(x)$ and $\gamma(y)$ represent weights on evaluation of the inside and outside stakeholders. The corporation is assumed to share larger interest with the inside stakeholders than with outside stakeholders. Innovation of ICT can decrease this communication gapes between the corporation and the outside stakeholder. It is assumed that raising effort $y_{i}$ of any stakeholders $i$ could improve communication environment surrounding the corporation. We simply express the above argument by $\gamma^{\prime}(y)>0$. Although Tanaka [4] provides optimal condition of $y_{i}$, this paper explores how the innovation transforms the structure of stakeholders. Any inside stakeholder $i\left(i=1, \ldots, n_{0}\right)$ might be supposed to enhance the trusty connection with the corporation as the production increases. $\beta(x)$ is an increasing function of corporation production $\left(\beta^{\prime}(x)>0\right)$.

$\beta(x)$ is assumed to be written to be independent of the total effort $y$. The structural efficiency of communication is analyzed formally by using coefficients $\beta(x)$ and $\gamma(y)$, when the inequality $1>\beta(x)>\gamma(y)$ holds for all $x, y$. Tanaka (13) discusses that the corporation in the centralized scheme brings social welfare losses under the incomplete objective function. It is appropriate that we construct a decentralized scheme to restore sustainability. However, digital economies in the enlarging global economies cannot be stopped expanding in the centralized scheme and are not expected to be governed sustainably in a decentralized framework. We should explore a scheme to improve sustainability of digital economies in the centralized system. Since innovations of ICT in digital economies have expanded internet services, some previous external stakeholders are more possible to make transaction with the corporation and to turn into outside stakeholders. The innovation of ICT is expected to change the structure of stakeholders. When digital economies are enlarging one type of stakeholder is easier to move into another type of stakeholder than before the digitalization of economies and societies. To discuss strictly structure changes of stakeholders brought by the digitalization of economies and societies, we explore the situation to be described as Assumption 2 .

Assumption 2: Stakeholders can choose freely inside and outside stakeholder to accompany changing behaviors between negative and positive stakeholders. The external stakeholders are difficult to become to take behaviors of inside stakeholders because of legislative and institutional constraints. However, the digitalization of economies and societies removes some obstacles for external stakeholders to obtain the benefit from taking outside stakeholders $^{5}$.

\section{Innovation of ICT and Contribution of Stakeholders}

As the scale of global economies grows, both positive and negative stakeholders increase. According to the argument of

${ }^{3}$ Tanaka(4) states that digital economies are approximately analyzed in the framework of centralization. Tanaka (11) makes clear that sustainability should be constructed in decentralized mechanism. Cassiers I, Maréchal and Méda ed., (12) p.6 explore empirical researches 'in-between' system.

${ }^{4}$ We write this expression by (2) in Tanaka (4) and abridge the original expression such as (1) in Tanaka (1).

${ }^{5} \mathrm{An}$ environmental organization to be distinguished into external stakeholders is possible to obtain stock of corporation and to participate management. In this situation, the environmental group is supposed to perform behaviors of negative stakeholders such as active shareholders. This paper explores in the following sections that the digitalization of economies and societies expands gapes of social welfare external stakeholders into other stakeholders. Although the diversification problems could be mitigated by declining external stakeholders, sustainability of communities is achieved by decentralizing digital economies. 
Tanaka [3] social welfare losses increase under incomplete sustainable mechanisms. Tanaka [4] discusses that digitalization of economies and societies could only partially decrease the social welfare losses and get rid of the vulnerability of the global social system. To become more sustainable, we must construct an incentive scheme for the corporation to reduce the social welfare $\operatorname{loss}^{6}$. The sustainable system of communication calculates social welfare by basing on the evaluation of all stakeholders and burdens the corporation a part of the social welfare loss. Tanaka [1],[9] and(11) demonstrate that the sustainable mechanism of communication is constructed by cooperation of all stakeholders. The sustainable network of communication is defined to be public goods and to be presented by total effort $y=\sum_{i=1}^{n} y_{i}$ provided by all stakeholders. The stakeholder $i$ provides voluntarily effort $y_{i}$ to improve the network of communication. Improving communication or transaction by internet services increase opportunities on businesses. At the same time, plastic waste problems reported in SNS move many countries restricting environmental regulation policies ${ }^{7}$. Quality and quantity of the network communication are determined by the total contribution $y$ of all stakeholder. It should be noticed that even external stakeholders can change behavior of the corporation by enhancing reviews, raising local funds and others.

Any stakeholder is assumed to make contribution $y_{i}$ to increase the social welfare brought by digital innovation. As the network of economies actually propels the digitalization of economies and societies, stakeholder $i$ aims to maximize targeted social welfare of the corporation by using $y_{i}$,

$W(y)=\beta(x) \Sigma_{i=1}^{n_{0}(y)}\left\{V_{i}\left(x, t_{i}\right)-y_{i}\right\}+\gamma(y) \sum_{i=n_{0}(y)+1}^{n_{1}(y)}\left\{V_{i}\left(x, t_{i}\right)-y_{i}\right\}+\sum_{i=n_{1}(y)+1}^{n}\left\{V_{i}\left(x, t_{i}\right)-y_{i}\right\}$

As inside and outside stakeholders are supposed to intent their contributions to reflect on the corporation, expression (2) writes same coefficients $\beta(x)$ and $\gamma(y)$ as (1). This objective function contains welfare of the external stakeholders that the corporation does not concern, because contributions all stakeholders yield innovation in the network society. To explore the influence of outside stakeholders on the innovation, we define welfare of outside stakeholders by

$$
W_{0}(y)=\sum_{i=n_{0}(y)+1}^{n_{1}(y)}\left\{V_{i}\left(x, t_{i}\right)-y_{i}\right\}(3)
$$

Noticing the $\frac{d y}{d y_{i}}=1$, the first order maximizing conditions of effort $y_{i}$ regarding inside, outside and external stakeholders are written by

$$
\gamma^{\prime}\left(y^{i}\right)=\frac{\beta(x)}{W_{0}\left(y^{i}\right)} \text { for inside stakeholders; } 1, \ldots, n_{0}(y)
$$

$$
\begin{aligned}
& \gamma^{\prime}\left(y^{0}\right)=\frac{\gamma\left(y^{0}\right)}{W_{0}\left(y^{0}\right)} \text { for outside stakeholders; } n_{0}(y)+1, \ldots, n_{1}(y) \\
& \gamma^{\prime}\left(y^{e}\right)=\frac{1}{W_{0}\left(y^{e}\right)} \text { for external stakeholders; } n_{1}(y)+1, \ldots, n .
\end{aligned}
$$

Feature of $\gamma(y)$ to be written in (2) and (3) describes a network of economies and societies. The above (4), (5) and (6) imply that the three types of stakeholders obtain different optimal contributions $y^{i}, y^{0}, y^{e}$. That is, all stakeholders attempt voluntarily to contribute innovation with different targets. Contributions by stakeholders on innovation are featured by Assumption 3.

Assumption 3: Marginal weight for outside stakeholders $\gamma^{\prime}(y)$ is supposed to be decreasing with total contributions in innovation of ICT. The welfare of outside stakeholders depends on their targeted contribution. In a temporal decision making every stakeholder of (2) does not transfer into another type of stakeholder. The relations; $\frac{d n_{0}(y)}{d y_{i}}=0$ and $\frac{d n_{1}(y)}{d y_{i}}=0$, are supposed
to be obtained.

Considering the inequality $1>\beta(x)>\gamma(y)$, we ensure that expressions (4),(5) and (6) bring the relation $y^{0}>y^{i}>y^{e}$ holds. This expression is explained as follows. The external stakeholders obtain lesser interest with improving efficiency of communication network than other stakeholders but participate on contribution on communication to improve audit and legislation by using the internet. Inside stakeholders actively utilize the network and seek to improve innovation of ICT to raise productivity by using new technologies such as IoT $^{8}$. Outside stakeholders are involved extensively in the rising businesses such as Fin Tech. In the digitalization of economies and societies this inequality shows that outside stakeholders provide larger potential contribution for innovation than other stakeholders. Increasing outside stakeholders become more probable to promote innovation of ICT. This result ensures the implication expressed by Proposition 1 .

Proposition 1: All three types of stakeholders contribute collectively the revolution to improve digital economies with diversified motivations. However, the effort of outside stakeholders makes more contribution than other types of stakeholders on expansion of innovation of ICT. The growth of outside stakeholders is a vital factor to promote digitalization of economies and societies.

Figure 1 is presented to illustrate implication of Proposition 1. A down sloping curve AE depicts $\gamma^{\prime}(y)$. Optimal solutions (4), (5)

${ }^{6}$ Tirole (14) initiates an incentive analysis on the corporate social responsibility.

'Oskam (15) considers the sharing economy in the community by analyzing Airbnb. Although the author does not employ any theoretical model, he discusses that outside and external stakeholders in this paper make significant responsibility on sustainability of the community.

${ }^{8}$ Saulles M (16) explores briefly the impact of IoT (Internet of Things) on business. 
and (6) are showed by points C, D and B. By reminding that total effort $y$ is summation of all efforts of stakeholders, the optimal conditions exhibit a cooperative solution of efforts. That is, the solution does not determine the share of effort brought by each stakeholder. Game theoretical approach could be applied to obtain definite effort of sharing. By using the above optimal conditions this paper describes the method to allocate efforts on stakeholders as follows. For $y ; y \leq y^{e}(6)$ shows that all stakeholders provide effort to improve innovation of communication. For $y^{e} \leq y \leq y^{i}$, (4) makes sure that outside and inside stakeholders provide effort. For $y ; y^{i} \leq y \leq y^{o}$, (5) states that only outside stakeholders provide effort to improve innovation of ICT. Figure 1 exhibits clearly that marginal expansion of innovation of digital economies is promoted mainly by effort of outside stakeholders. Consequently, innovation of ICT and digitalization of economies and societies are brought by the growth of outside stakeholders.

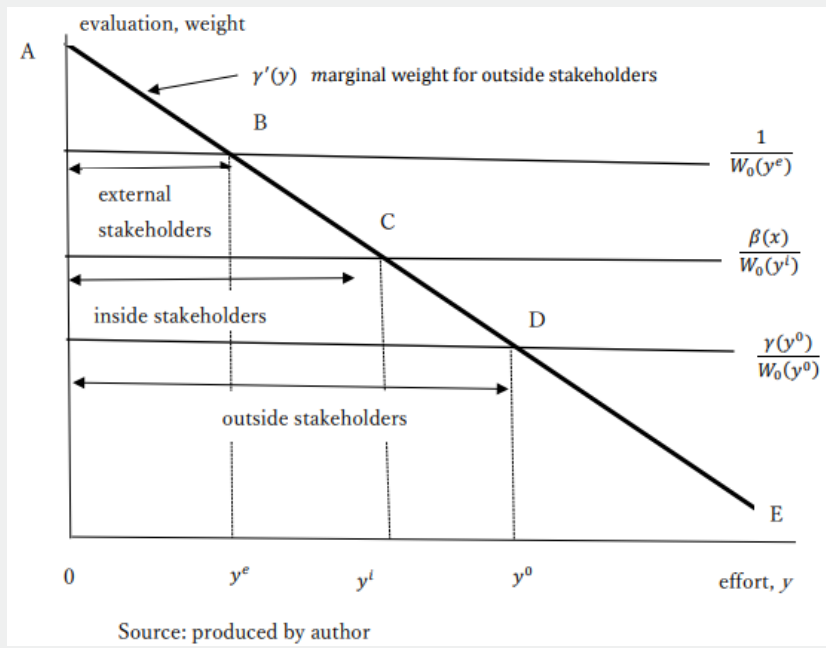

Figure 1: Contributions for innovation that each stakeholder contributes.

\section{Transaction Costs and Structure of Stakeholders}

Corporations in digital economies have become to combine firmly with global networks of economies and societies. It is supposed that the digitalization of economies and societies causes rearrangement of global industrial networks. Corporations should reform their own production networks to survive great fluctuations brought by the industrial revolution ${ }^{9}$. Corporations must not only seek to achive maximization of private profit but also to pursuit integrated governance of inside and outside stakeholders. Integrated organizational governance of total structure of stakeholders could produce new businesses to promote digitalization of economies and societies. In 2010, Williamson suggests "the common view of contract as legal rules thus gives way to the more elastic concept of contract as framework ${ }^{10}$. Evolution of digital economies accompanies improvement of the integrated governance on the corporation and expanding stakeholders. In particular, innovation of ICT develops temporal and various cooperation and evolves connection of stakeholders with internet services. Tanaka [4] suggests that the new concept of transaction cost presents a sensitive index to measure the performance of integrated corporate governance in digitalization. This paper enhances the theoretical foundation on this argument.

Globalizing economies have expanded industrial and social organization of networks. Large international organizations seek benefits of networks but bring inevitably large amount of social costs at the same time. If the social costs are estimated to be uprising beyond a limit, efficient schemes to govern them should enhance significance to achieve sustainability. The famous Coase's Theorem indicates that the transaction cost causes social welfare loss ${ }^{11}$.

Transaction costs are supposed inevitably to occur in digital networks of societies in different forms from traditional industrial organizations. As the digital networks are prevailing, we should make theoretical foundation on this transaction approach to digital network societies. It is assumed in this model that stakeholders could improve their welfare in the process of communication or transaction with the corporation. If the corporation accurately recognizes the evaluation of the stakeholders, they could achieve efficient communication with least transaction costs. In this theoretical analysis the weights for the stakeholder in the

${ }^{9}$ This paper develops a theoretical approach of organization for the digitalization of economies and societies. In an empirical research Choudrie, Tsatsou \& Kruria (17) argue the importance of social inclusion by ICT services.

${ }^{10}$ This is cited in page 16, Williamson (18) and he explores a rough indication of the framework.

${ }^{11}$ Coase (19) points out that not only price mechanism in market but marginal costs regarding bargaining or contract works an equilibrating force for organizations. 
expression (1) present the index of efficiency in the communication mechanism. As the upper limit of the weight is assumed to be one and to express the most efficient communication, it's gap from one is defined as the transaction cost in the mechanism. As external stakeholders have not opportunities to contact continuously with the corporation, the transaction cost is assumed to be raised to upper bound one. The transaction costs have different values for three types of stakeholders and can analyze the feature of network system in the digital economies. Suppose that the corporation takes the transaction costs with the inside, the outside and the external stakeholders by $C_{i}, C_{0}, C_{e}$ the transaction costs are defined mathematically by $C_{i}(x)=1-\beta(x)$ for inside stakeholders,

$$
\begin{aligned}
& C_{0}(y)=1-\gamma(y) \text { for outside stakeholders, } \\
& C_{e}=1-0 \text { for external stakeholders. }
\end{aligned}
$$

Centralized structure of production defined by (1) brings transaction costs as theoretical methods for digitalization of economies and societies. From the assumption $\beta^{\prime}(x)>0$ decreasing transaction of inside stakeholders $C_{i}(x)<0$ is derived. In particular, expanding production of global economies lowers the transaction cost of inside stakeholders. The inequality $\gamma^{\prime}(y)>0$ takes decreasing transaction cost of outside stakeholders with enlarging digital economies $C_{0}{ }^{\prime}(y)<0$.

Innovation of ICT causes lowering transaction cost of outside stakeholders. And the transaction cost of outside stakeholders is assumed to be indifferent of production levels and to depend on innovation of digital economies. By featuring transaction cost functions in global and digital economies we can illustrate the structural changes of societies in the new industrial revolution ${ }^{12}$. The fundamental reform of stakeholders could explain a mechanical design of the new industrial revolution. The theoretical model argues that the globalizing and digital economies have different impacts on each type of stakeholders. The stakeholders make different decisions according to their own interests. Consequently, their individual behaviors bring revolutionary reform on construction of stakeholders. The stakeholders are supposed to respond on the decision makings of the corporation. In the optimal expression of mathematics, the corporation maximizes net benefit function (1) with $x, t_{i}\left(i=1, \ldots, n_{1}(y)\right)$. The first order conditions of maximization are written by (7), (8), (9) ${ }^{13}$.

$\frac{d \Pi}{d x}=\Sigma_{i=1}^{n_{0}(y)}-\left\{\frac{d \beta(x)}{d x}\left(V_{i}\left(x, t_{i}\right)-y_{i}\right) \beta(x) \frac{\partial V_{i}\left(x, t_{i}\right)}{\partial x}\right\}-\gamma(y) \Sigma_{i=n_{0}(y)+1}^{n_{1}(y)} \frac{\partial V_{i}\left(x, t_{i}\right)}{\partial x}$.

$\frac{\partial V_{i}\left(x, t_{i}\right)}{\partial x}=\frac{1}{\beta(x)} i=1, \ldots, n_{0}(y)$. $\frac{\partial V_{i}\left(x, t_{i}\right)}{\partial x}=\frac{1}{\gamma(y)} i=n_{0}(y)+1, \ldots, n_{1}(y)$

To investigate completely organization of digitalization we should articulate behavior of the corporation for contributions on external stakeholder. The articulation ought to be comparable with (8) and (9). The contribution of corporation on external stakeholders $\mathrm{i}$ is expressed formally by $t_{i}=0, \frac{\partial V_{i}(x, 0)}{\partial t_{i}}>0^{14} i=n_{1}(y)+1, \ldots, n$ (10). The above expression (10) implies that the corporation in a centralized system does not directly provide any payment for external stakeholders.

\section{Digitalization of economies and societies}

In this section, we investigate the mechanism that brings innovation of ICT a structural change of stakeholders. Expressions (8), (9), (10) explore theoretically mechanisms of industrial revolution in the context of stakeholder's structure. This paper argues that stakeholders are classified into 3 types. As one type of stakeholders are supposed to obtain various evaluation on performance of the corporation, marginal evaluation of payment $\underline{\partial V_{i}\left(x, t_{i}\right)}$ varies for individual stakeholder $i$. By exhibiting (Figure 2,3 ) marginal evaluation curves represent relative evaluation among 3 type of individual stakeholder. However, the curves in each type are possible to be depicted by another curve to keep the same relative position as (Figure 2). Inequality, $C_{0}{ }^{\prime}(y)<0$, means that innovation of ICT is supposed to decline the transaction cost regarding outside stakeholders. By using (Figure 2) this section demonstrates that the decreasing transaction cost causes a revolutionary change in the social system ${ }^{15}$. In the first, we explore the direct effect brought by the innovation in the outside stakeholder. The expression (9) exhibits payment condition that the corporation offers for outside stakeholders. As the innovation proceeds, according to the inequality $\gamma^{\prime}(y)>0$ the right side of (9) to be depicted by the line GG' lowers to $\mathrm{HH}^{\prime}$. The left side of (9) is expressed by the curve BD. The expanding innovation of ICT moves the equilibrium point $J$ with outside stakeholders to $\mathrm{L}$ and increases economic surplus to be expressed by area of the triangle BGJ to that of BHL. This rising surplus means that the digitalization of economies and societies improves welfare of outside stakeholders. From above reasoning we could conclude that outside stakeholders obtain net benefits in this industrial revolution. This type of stakeholder has an incentive to involve actively the digital transaction. In the second, we consider how this revolution influences on inside stakeholders. We demonstrate the possibility that an inside stakeholder turns into the outside stakeholder in some situations ${ }^{16}[21]$. The right

${ }^{12}$ Rifkin (20) explores extensively development of ICT and concludes that innovation of ICT decreases marginal production cost of IoT.

${ }^{13}$ In discussions on social systems, Tanaka (1), (3) and (11) investigate the possibility that innovation raises the production levels and reduces social welfare losses.

${ }^{14}$ The evaluation function of the stakeholder $\mathrm{i}$ is supposed to be a concave function.

${ }^{15}$ Tanaka (21) attempts to develop similar discussion. However, this paper improves the previous research more completely by adding analysis of social welfare.

${ }^{16}$ Paus (22) does not use the terminology of stakeholders but investigates the transforming workplaces of outside stakeholders referred in this paper. The author states "digital taking platforms have become online labor market where people offer short-term and micro tasks. Paus p12." To improve social welfare this book, suggest social reform by activating external stakeholders. 
side of the expression (8) is depicted by the line II'. By supposing that inside stakeholders are formed in smaller scale than outside stakeholders. The marginal evaluation curve with payment to be presented by AE is steeper than the curve for outside stakeholder BD. And starting point $\mathrm{A}$ is located higher than the relevant point $\mathrm{B}$ of outsider stakeholders. This industrial revolution is supposed to be possible by the change that some stakeholders move one to another type of stakeholders. This section confirms theoretically the possibility to transform stakeholders from the inside to the outside stakeholders. In the digitalization of economies and societies, the inside stakeholder obtains two alternative surpluses triangles AIK in inside stakeholders and BHL in outside stakeholders. In (Figure 2) AI is larger than BH, but IK is smaller than HL. If innovation of ICT expands BH and $\mathrm{HL}$ aera of triangle BHL for outside stakeholders grows. The surplus of outside stakeholders becomes more dominant than that of inside stakeholders. Firms to have been combined into a big corporative organization become possible to have more profitable opportunities in the flexible organization of business network. The digitalization of economies and societies induces inside stakeholders to transfer into outside stakeholders.

In the third, we explore ramification of the digitalization of economies and societies to external stakeholders. In (Figure 2) the curve CF depicts the marginal evaluation of external stakeholder regarding payments of the corporation. (Figure 2) illustrates implication of the expression (10). As the external stakeholder does not belong to the corporative organization, the line of inside stakeholders II' is not relevant to external stakeholders. In the previous situation outside stakeholders become to obtain more surplus than before the digitalization. As this change is not relevant with external stakeholders, the gap of social welfare between outside and external stakeholders increases and induce transfer of external stakeholders into outside stakeholders. In the process of industrial revolution external stakeholders are assumed to obtain two options. One is to turn into inside stakeholders such as suppler in IoT and the other is to join transactions of outside stakeholders such as providers in share businesses. For external stakeholders the opportunity to turns into inside stakeholders is limited, and places of outside stakeholders are growing. We discuss the possibility for external stakeholders to take a place of outside stakeholder. However, the opportunities of transfer are not available for every external stakeholder. Some external stakeholders are privileged to behave as outside stakeholders but the others are obliged to be excluded from this transformation. The residents who could not follow the transformation suffer problems of diversification. Some external stakeholders could take befits form innovation of ICT. Before the digitalization of economies and societies, line $\mathrm{GG}^{\prime}$ and curve $\mathrm{CF}$ have not any intersection. It means before the new industrial revolution that external stakeholders do not receive any payment. So, they cannot obtain any surplus. In the former case, they remain to be external stakeholders and calculate benefits, area CHM according to curve CF. NGO advocates social responsibility of corporation positively by using the internet. Digitalization improves the environment that external stakeholders persuade the corporation their interests. Curve BD presents opportunities that the innovation provides them profitable benefits indicated by area of triangle BHL. In the latter case, before they have not used enough efficient facilities, after industrial revolution digital transactions are available for some stakeholders. In the two situations, the shift of the line GG' to $\mathrm{HH}^{\prime}$ raises surplus of the external stakeholders by area of triangles BHL or CHM. If external stakeholders could follow performance of outside stakeholders, they can improve welfare. Enhancement of surplus promotes flow of stakeholders from the external to the outside. Consequently, we prove a possibility theorem that innovation of ICT concentrates stakeholders on the outside. The results are summarized as Proposition 2.

Proposition 2. Innovation of ICT brings about transfer of stakeholders from inside and external ones to outside ones. In this process, outside stakeholders increase absolutely and relatively.

Proposition 2 presents a possibility theorem in the situation to be represented by (Figure 2). However, many prosperous economies are expected to clear the requirements of the digitalization of economies and societies. In this situation, $n_{0}(y)$ and $n_{1}(y)$ are mathematically expressed by decreasing and increasing function with $y$. This proposition explains that the structural change of stakeholders ignites explosion of digitalization of economies and societies. Theoretically, $W_{0}(y)$ begins to rise. In the following step, the right side of expressions (5) declines, social effort on innovation increases and right side of expression (9) lowers. The reasoning in Proposition 2 is applicable to explain expanding spirals of industrial revolution. As the corporation greatly concerns with enhancement of productivity and the digital innovation, transaction costs are useful index for management. In the context of analyses using transaction costs we can verify implication of Proposition 2. If innovation of ICT decreases transaction cost regarding outside stakeholders, transfer into outside stakeholders begins and triggers great waves of digitalization of economies and societies. Comparative analysis of transaction cost with stakeholders could effectively investigate the network structure of economies and societies.

\section{Concluding Remarks}

Tanaka $[4,23]$ discuss that outside stakeholders to be swelled by digitalization of economies and societies have been reforming social network systems and global production and distribution mechanisms. As digital network systems have been developed, outside stakeholders raise influence on featuring the digitalization of economies and societies. By reminding that outside stakeholders are defined to belong to the negative stakeholder, performance of corporation to have grown in globalizing economies becomes to be more vulnerable or sensitive with factors to be uncontrollable by market mechanism. (Figure 2) of Tanaka [4] indicates a possibility that increasing outside stakeholders make production system more decentralized and lower production. A local issue might become more probably to cause global problems in the 


\section{Annals of Social Sciences \& Management studies}

digital social system. In a short term, Covid-19 Pandemic declines the weight on evaluation of outside stakeholders and raises their transaction cost. For example, global networks have facilitated advanced digital technologies to distribute goods and services such as air transportation service of LCC but Pandemic is expected to raise transaction costs to break down global economics performance. In this case, social system proceeds on the opposite direction to the assumptions in Proposition 2. The line HH' in
(Figure 2) moves upwardly. The relative advantage of outside stakeholders regarding social surplus verses inside stakeholders lowers. In the sustainable framework such presented by such as Tanaka (1) risk coefficient is expected to increase. Consequently, in the long perspective, decentralized economic systems partially will displace centralized system and global production system should be reformed sustainably.

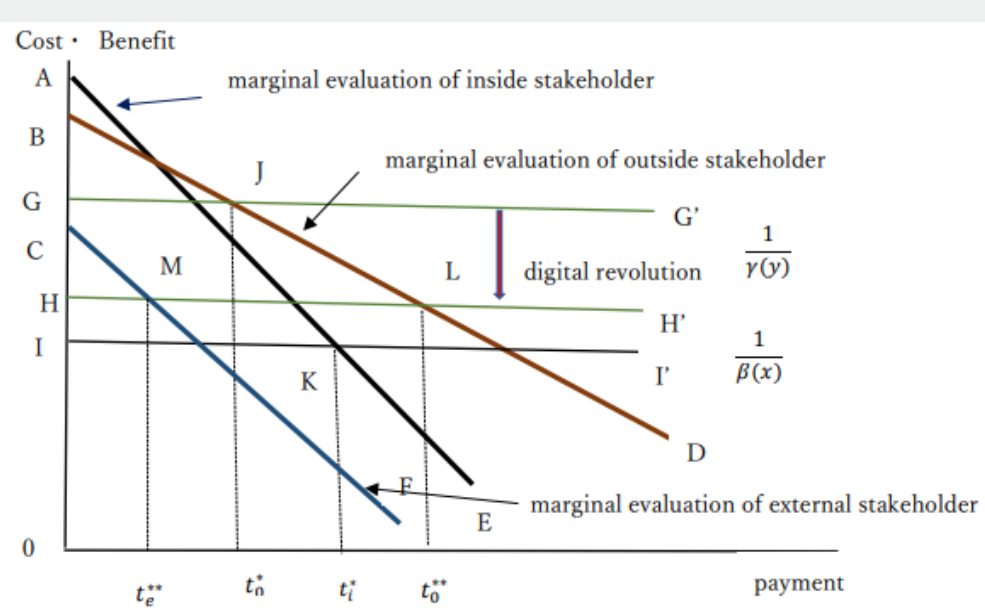

Source: Produced by author

Figure 2: Innovation and Restructure of Stakeholders.

\section{References}

1. Tanaka H (2017) Sustainability of Global Communities and Regional Risk Governance. Asia Pacific Journal of Regional Science, 1(2): 639653.

2. Baecker RM (2019) Computers and Society: Modern Perspectives, Oxford University Press, Oxford, UK.

3. Tanaka H (2018) Mechanism of Sustainability and Structure of Stakeholders in Regions. Financial Forum, 7 (1): 1-12.

4. Tanaka H (2019b) Innovation on the Digital Economies and Sustainability of the Global Communities. Annals of social sciences \& management studies, Juniper 4(2):1-10.

5. Williamson OE (1975) Markets and Hierarchies: Analysis and Antitrust Implication. The Free Press, New York.

6. Williamson OE (1979) Transaction-Cost Economics: The Governance of Contractual Relations. Journal of Law and Economics, 22(2): 233261

7. Williamson OE (1986) Economic Organization: Firms, Markets and Policy Control, Wheatsheaf Books, Brighton, UK.

8. Williamson OE (1990) Industrial Organization. Edward Elgar Publishing, Cheltenham, UK

9. Tanaka H (2004) Kigyo no Syakaiteki Sekinin no Keizai Riron Japanese, Theoretical Analysis for Corporate Social Responsibility. Chikyuu Kankyu Report Japanese, Global Environmental Policy in Japan, 9: 1-9.

10. Hindman M (2018) The Internet Trap: How the Digital Economy Builds Monopolies and Undermines Democracy, Princeton University Press, Princeton, USA.
11. Tanaka H (2016) The Sustainability Theorem in the ESG Mechanism. Long Finance and London Accord, pp,1-29.

12. Cassiers I, Maréchal K \& Méda D (2018) Post-growth Economics and Society: Exploring the Paths of a Social and Ecological Transition, Routledge, Abingdon, UK.

13. Tanaka H (2019a) Rehabilitation of the Decentralization in the Centralizing Process of Global Communities. Journal of Global Issues and Solutions, 19(3):1-18.

14. Tirole J (2001) Corporate Governance. Econometrica, 68(1): 1-35.

15. Oskam JA (2019) The future of Airbnb and Sharing Economy: The Collaborative Consumption of our Cities, Channel View Publications, Bristol, UK.

16. Saulles (2017) The Internet of Things and Business, Routledge, Abington, UK.

17. Choudrie J, Tsatsou P \& Kruria S (2018) Social Inclusion and Usability of ICT-Enable Services, Routledge, Abingdon, UK.

18. Williamson OE (2010) Transaction Cost Economics: an overview. In Klein PG \& Sykuta ME (eds.), The Elgar Companion to Transaction Cost Economics, Edward Elgar Publishing, Cheltenham, UK.

19. Coase RH (1937) The Nature of the Firm. Economica, 4(16): 386-405.

20. Rifkin J (2014) The Zero Marginal Cost Society: The internet of Things, The Collaborative Commons, and The Eclipse of Capitalism. St Martin's Press, New York.

21. Tanaka H (2020) Digital Revolution and Structural Reform of Stakeholders. Journal of Global Issues and Solutions, 20(2): 1-7. 
22. Paus E (2018) Confronting Dystopia: The New Technological Revolution and the Future of Work, Cornel University Press, New York, USA.
23. Tanaka H (2019c) Sustainable Governance of Marine Stakeholders. Oceanography \& Fisheries Open Access Journal, Juniper 11(1): 1-4
This work is licensed under Creative Commons Attribution 4.0 License

DOI: 10.19080/ASM.2020.05.555670
Your next submission with Juniper Publishers will reach you the below assets

- Quality Editorial service

- Swift Peer Review

- Reprints availability

- E-prints Service

- Manuscript Podcast for convenient understanding

- Global attainment for your research

- Manuscript accessibility in different formats

( Pdf, E-pub, Full Text, Audio)

- Unceasing customer service

Track the below URL for one-step submission https://juniperpublishers.com/online-submission.php 